Jakub Sadowski

Uniwersytet Jagielloński

e-mail: jakub.sadowski@uj.edu.pl

\title{
Filmowy Poemat pedagogiczny: między Makarenką a wymogami kultury totalitarnej
}

\section{Summary}

Cinematic Pedagogical Poem: between Makarenko and the requirements of totalitarian culture

Anton Makarenko's novel The Pedagogical Poem had been published in 1934-1935; after 20 years it was finally filmed (The Pedagogical Poem by Alexei Maslukov and Mechislava Mayevskaya, 1955). This article is an analysis of a specific relationship between Makarenko's text and the cinematic variant of the "Poem". The nature of transformation of literary text into film text is complex. It requires not only the adaptation of the novel to the linguistic requirements of the movie. The typological distinctions between the language of literary and cinematic Poems concern not only two spheres of the functioning of these works, but also two types of culture in which they were brought to life. The literary Pedagogical Poem was created as an autonomous work against totalitarian discourse, however it still participates in it. The key to its reading (which is specific for totalitarian culture) analyzed in this text results from the main function of narratives of this culture, i.e. the transmission of units of its mythological universe.

Keywords: Anton Makarenko, The Pedagogical Poem, Soviet Union, cinema, film, Stalinist culture, totalitarianism

Słowa kluczowe: Anton Makarenko, Poemat pedagogiczny, Związek Radziecki, kino, film, kultura stalinowska, totalitaryzm

Pierwsza część Poematu pedagogicznego Antona Makarenki ujrzała światło dzienne w 1934 roku, dwie kolejne - rok później. Bez względu na wielką liczbę edycji powieści na wydanie pełnego tekstu dzieło musiało czekać niemal 80 lat (Makarienko 2003, Niewskaja 2003: 11). Znacznie krócej, bo 20 lat, czekało na swoją ekranizację - epicki dramat filmowy w reżyserii Aleksieja Maslukowa i Mieczysławy Majewskiej (Piedagogiczeskaja poema, 1955). Niniejszy tekst traktuje o relacji między tekstem Makarenki i kinematograficznym wariantem Poematu. Nie chodzi tu jednak o ogólną relację obu dzieł - złożoną ze względu na oczywisty fakt, iż każda ekranizacja z konieczności jest skutkiem transformacji dzieła powstałego w obrębie systemu semiotycznego (języka) typologicznie innego niż właściwy filmowi fabularnemu. Interesować nas tu będą jedynie te aspekty transformacji filmowej, które jednocześnie wiążą się z faktem, iż wyjściowego 
Poematu pedagogicznego - bez względu na jego realizm oraz ideologiczny komponent nie można jednoznacznie zaklasyfikować jako dzieło socrealistyczne, podczas gdy obraz Maslukowa i Majewskiej, transmitując w preferowanej przez kulturę stalinowską formie elementy jej mitologicznego uniwersum, spełnia wszystkie wyznaczniki przynależności do konwencji realizmu socjalistycznego (Sadowski 2009: 80-94, Sadowski 2017). Tym samym dramat filmowy dwojga radzieckich reżyserów transmituje nieco inne treści niż tekst słynnego pedagoga.

Zasadnicze różnice między tekstem Makarenki a jego filmowym wcieleniem, stanowiące o ideologicznej funkcji tego ostatniego, zostały już w literaturze naukowej omówione. Jest to zasługą Wadima Michajlina i Galiny Bielajewej - autorów wnikliwego i błyskotliwego studium (Michajlin, Bielajewa 2014), poświęconego zresztą nie tylko Poematowi pedagogicznemu, lecz również jego „krewnym” w kinematografii rosyjskiej, reprezentującym specyficzny „mikrogatunek resocjalizacyjny”. Zadanie niniejszego tekstu jest jednak bardziej szczegółowe i sprowadza się do analizy jedynie niektórych aspektów wzajemnych relacji literackiego pierwowzoru i jego ekranizacji - takich, które stanowią o specyficznym, totalitarnokulturowym sposobie transformacji tekstu wyjściowego i które dostosowywały tekst Makarenki do odbioru w kluczu charakterystycznym dla kultury stalinowskiej.

Tu trzeba jednak poczynić drobne, ale istotne zastrzeżenie: film Maslukowa i Majewskiej powstał wprawdzie w obrębie kultury totalitarnej, ale w okresie jej stopniowego rozkładu. Kultura oficjalna ZSRR w roku premiery filmu nosiła wciąż jeszcze wszystkie cechy modelu kulturowego, uformowanego w latach trzydziestych pod rządami Stalina - jednak korpus jej treści zdążył już samą postać Stalina „zapomnieć”, wyprzeć, „odfiltrować". Umożliwiła to zapoczątkowana niemal od razu po śmierci sekretarza generalnego w 1953 roku strategia Biura Politycznego CK KPZR, polegająca na radykalnym odwrocie od kultu wodza w oficjalnej retoryce politycznej i polityce symbolicznej. Skutki tej strategii doskonale widać w filmowym Poemacie pedagogicznym, w pełni zachowującym strukturę narracji totalitarnej, pozbawionym jednak - na poziomie treściowym - odwołań do niedawnej figury kultu. Z kolei dzieło samego Makarenki, pisane przezeń niemal 10 lat i ukończone bezpośrednio przed wydaniem, powstawało w realiach kultury rewolucyjnej lat dwudziestych i dopiero krystalizującej się kultury totalitarnej. Jego struktura narracyjna nie jest podporządkowana transmisji mitologii politycznej, na poziomie treściowym bezpośrednie odwołania ideologiczno-polityczne pojawiają się w nim z różną intensywnością: stosunkowo rzadko w części pierwszej (której zrąb powstał w latach 1925-28), znacznie częściej w drugiej i trzeciej (pisanych w latach trzydziestych).

Szczególne relacje między tekstem wyjściowym i filmem można prześledzić już u zawiązania fabuły. Następuje ono w momencie rozmowy pierwszoosobowego narratora w tekście literackim i postaci Makarenki w filmie (w tej roli - Władimir Jemieljanow) z kierownikiem Wydziału Gubernialnego Oświaty Ludowej (w filmie wciela się w niego Konstantin Bartaszewicz). To tu następuje powierzenie Makarence funkcji szefa przyszłej Kolonii im. Gorkiego. W filmie kluczowy dialog przedstawia się następująco: 
Kierownik: Bezdomnych widziałeś?

Makarenko: Widziałem.

Kierownik: Znasz stanowisko rządu w sprawie likwidacji bezdomności nieletnich?

Makarenko: Znam.

Kierownik: A o tym, że na tym froncie sprawy idą kiepsko - też wiesz?

Makarenko: Jeśli szczerze, to nie bardzo.

Kierownik: Zgarniamy bezdomnych. Mamy domy dziecka... A wychowawców, mądrych, z inicjatywą, ze świadomością bolszewicką - mało mamy. Mam tu ludzi - zakopali się w papierach, okopali się w książkach. A gdy dać im żywego człowieka - to rękoma i nogami będą się bronić. Powiedzą: „Zarżną nas przecież”!

Makarenko: A jeśli ja się za to wezmę... Przecież na pewno powiedzą, ze robię coś nie tak. Sam nie wiem... Nowego człowieka trzeba tworzyć po nowemu. A jeśli rzeczywiście coś zrobię nie tak?

Kierownik: „Nie tak, nie tak...!” A my poprawimy! Wszyscy musimy bazować na doświadczeniu. Najważniejsza sprawa - to wychować człowieka radzieckiego. Więc go wychowuj. (Piedagogiczeskaja poema, 1955)

Dialog filmowy różni się od literackiego niewielkimi, ale wymownymi szczegółami. W pierwszej jego części takim szczegółem jest przede wszystkim sformułowanie ideologicznego wymogu wobec wychowawców - w pierwowzorze kierownik nie apeluje do „świadomości bolszewickiej”. Powieściowy pierwszoosobowy narrator zachowanie swego rozmówcy kwituje w następujący sposób:

Kierownik przewiercał mnie na wskroś złymi, maleńkimi, czarnymi oczkami [w oryg.: сердито покалывал меня маленькими черными глазами $]^{1}$, a spod nietscheańskich wąsów rzucał kalumnie na całą naszą brać pedagogiczną. Ale przecież ten kierownik Wydziału Gubernialnego Oświaty Ludowej nie miał racji (Makarenko 1949: I, 6).

Olbrzymie znaczenie ma końcowe stadium przytoczonego dialogu, rozpoczęte Makarenkowskim „A jeśli rzeczywiście coś zrobię nie tak?”. W książce przedstawia się ono następująco:

- No, a jeżeli ja rzeczywiście nawarzę piwa?

Kierownik huknął pięścią w stół.

- Czego ciągle powtarzasz - nawarzę, nawarzę!... No to nawarzysz! Czego chcesz? Czy ja już nic nie rozumiem, czy co? Nawarzysz, ale robić coś trzeba. A potem - zobaczymy. Najważniejsze, żeby to nie była jakaś kolonia dla nieletnich przestępców, tylko rozumiesz chodzi o wychowanie socjalistyczne... Potrzebny nam jest człowiek, nasz człowiek! Twórz go. A uczyć się muszą wszyscy. I ty także będziesz się uczył. Dobrze, żeś tak po prostu powiedział: nie wiem. To dobrze (Makarenko 1949: I, 7).

\footnotetext{
1 A zatem to nie oczy kierownika były „złe”, lecz jego spojrzenie - „złe” czy wręcz „wściekłe”.
} 
Błyskotliwą analizę filmowej transformacji postaci kierownika przedstawiają Michajlin i Bielajewa:

W tekście wyjściowym nie ma żadnej epickiej figury człowieka partyjnego z manierami pewnego siebie gospodarza i z wiarą w umiejętności nie mniej pewnego siebie Makarenki. Jest natomiast mały, rozbiegany, gubiący się w swoich słowach urzędnik w randze kierownika wydziału. Po drugie, ten drobny funkcjonariusz radziecki ze wszystkimi swoimi pretensjami antyinteligenckimi zwraca się... do samego Makarenki. W rezultacie źródło literackie daje nam protagonistę w postaci samotnego, mądrego i inteligentnego bojownika z tępym systemem, względem którego występuje on raczej w roli najętego zewnętrznego specjalisty, film natomiast - postać wiernego syna Partii, współdepozytariusza wiedzy ezoterycznej o jedynie słusznym - partyjnym - podejściu do przezwyciężenia dowolnych trudności (Michajlin, Bielajewa 2014).

Faktycznie, w filmie następuje ,upartyjnienie” postaci Makarenki, której realny pierwowzór pozostawał skądinąd bezpartyjny (zaś narrator literackiego pierwowzoru do statusu „partyjności” nie aspirował). Kultura totalitarna opiera się jednak na mitologicznym obrazie świata, cechą zaś takiego obrazu jest m.in. niemożność nadania pozytywnej charakterystyki aksjologicznej zjawisku ocenianemu negatywnie pod jakimkolwiek innym względem estetycznym - i na odwrót (Sadowski 2009: 70-73). W dyskursie totalitarnym postać Makarenki, uzyskująca status autorytetu pedagogicznego, by taką pozostać, musi być jednocześnie autorytetem politycznym, czyli nosicielem świadomości partyjnej. Podobnie zresztą urzędnik radziecki nie może nie mieć gotowej recepty na resocjalizację małoletnich przestępców. Dlatego w filmie nie wypowiada literackiej frazy: „Może i nawarzysz piwa, ale robić coś trzeba. A potem - zobaczymy". Doskonale wie, komu oddaje władzę w kolonii - wychowawcy „mądremu, z inicjatywą, ze świadomością bolszewicką”, gdyż w obrębie totalitarnej świadomości mitologicznej to właśnie „,bolszewicka wiadomość" jest rękojmią skutecznej resocjalizacji. W żaden też sposób postać kierownika nie może sprawiać wrażenia, iż mogłaby się do niego odnosić konstatacja Makarenkowskiego narratora: „Ale przecież ten kierownik Wydziału Gubernialnego Oświaty Ludowej nie miał racji”. „Prawidłowy”, czy też - ,prawdziwy” człowiek partii na innego „prawdziwego” z pewnością nie spogląda w sposób „zły” czy „wściekły” (jak u Makarenki), lecz ze spokojem, pewnością swojej racji i zrozumienia u rozmówcy. Musi umieć rozpoznać i zdefiniować błąd wychowawczy, stąd też - o ile filmowy pedagog go popełni, musi umieć zapewnić, że „my” - czyli partia - „poprawimy”. Niewystępujące w pierwowzorze literackim kategorie człowieka partyjnego i „świadomości bolszewickiej” w filmie pełnią funkcję mitologemu, transmitując określony światopogląd, są figurą właśnie światopoglądowego opisu rzeczywistości i źródłem specyficznej prekognicji: kierownik w i e, że powierzenie Makarence funkcji szefa kolonii prowadzi do resocjalizacji w duchu bolszewickim.

Funkcję mitologemu pełni też sformułowanie zadania stawianego w filmie przed postacią Makarenki: „Najważniejsza sprawa - to wychować człowieka radzieckiego”. Fraza 
ta nie odpowiada użytej przez autora pierwowzoru kategorii „wychowania socjalistycznego". W kulturze rewolucyjnej, w obrębie której dokonywały się działania Makarenki w kolonii i w której powstawało dzieło literackie, ,wychowanie socjalistyczne” nosiło, owszem, marker ideologiczny, ale nie mitologiczny, będąc postulatem „nowego" wychowania, pozbawionego przedrewolucyjnych obciążeń. Charakterystyczny dla kultury rewolucyjnej antropologiczny postulat "nowego człowieka” miał charakter utopijny, wynikający z przekonania o możliwości modelowania jednostki „od zera”, z pominięciem społecznych przedrewolucyjnych obciążeń (Sadowski 2005: 53-81). „Człowiek radziecki” natomiast to totalitarnokulturowa figura herosa, która - osiągnąwszy ideologiczną dojrzałość i w pełni zespoliwszy swoją świadomość z polityczno-mitologicznym swojej wspólnoty, nabiera cech jednostki idealnej, w pełni realizującej swój potencjał. W odniesieniu do małoletnich przestępców zrobić z nich „ludzi radzieckich” - znaczy tyle, co skutecznie i w pełni obudzić ich potencjał oraz dać gwarancję jego realizacji w przestrzeni społecznej. Gwarancją skuteczności takiego działania jest „świadomość bolszewicka” wychowawcy. zaś dowodem tej skuteczności - choćby postać Zadorowa, z którą na samym początku zasadniczej części fabuły, opowiadającej o życiu kolonii, wiąże się pierwsza dramatyczna konfrontacja Makarenki z podopiecznymi. Pod koniec filmu, po przejęciu przez Kolonię im. Gorkiego ośrodka w Kuriażu, Zadorow jest w stanie powiedzieć jego niezresocjalizowanym jeszcze mieszkańcom: „Jestem najpierwszym kolonistą-gorkowcem. Najstarszym, a kiedyś byłem najgorszym. A teraz jestem już studentem pierwszego roku instytutu technologicznego". Fraza ta występuje zarówno w filmie, jak i w jego pierwowzorze (Piedagogiczeskaja poema, 1955, Makarenko 1949: III, 149), w fabule ekranizacji pełni jednak funkcję dowodu prawdziwości mitologemu, podczas gdy u samego Makarenki jego funkcja jest czysto fabularna: za pomocą swojej wypowiedzi Zadorow pomaga opanowaniu nieufności „nowych gorkowców” względem „starych”. Widać zatem, że totalitarna transformacja komunikatu w żaden sposób nie musi dotyczyć jego formalnej struktury; ingeruje jednak w jego ładunek semantyczny i modyfikuje funkcję pragmatyczną.

Konfrontację z Zadorowem narrator Makarenki opisuje z pozycji osoby przyznającej się do bezsilności. W czasie pierwszej zimy w kolonii krnąbrny podopieczny w wyzywający i chamski sposób odmawia narąbania drew do kuchni. Wyprowadzony z równowagi Makarenko uderza go w twarz, wykrzykując przy tym do zgromadzonych: „Albo wszyscy natychmiast na robotę do lasu, albo precz z kolonii na wszystkie wiatry!" (Makarenko 1949: I, 19). Mimo iż wybuch pedagoga przynosi pozytywny efekt wychowawczy, zarówno on sam, jak i jego współpracownicy są zdruzgotani. Wkrótce dochodzi do następującego dialogu między nim a wychowawczynią Jekatieriną Grigoriewną (w polskim tłumaczeniu - Katarzyną):

- [...] Najbardziej przykre jest to, że przecież chłopcy opowiadają o waszym wyczynie z zachwytem. Gotowi są nawet zakochać się w was, a pierwszy Zadorow. Co to jest? Nie rozumiem. Duch niewolnictwa?

- Nie, nie chodzi tutaj o niewolnictwo. To coś innego. Zanalizujcie dokładnie: przecież Zadorow jest ode mnie silniejszy, jednym uderzeniem mógłby mnie położyć. I przecież nie boi 
się on niczego, nie boi się Burun i inni. W całej tej historii oni nie widzą bicia, widzą tylko gniew, wybuch ludzkiego gniewu. Rozumieją przecież doskonale, że mogłem nie uderzyć, mogłem skierować Zadorowa jako niepoprawnego do komisji, mogłem im zrobić wiele poważnych przykrości. Ale tego nie robię. Uciekłem się do postępku, który był niebezpieczny dla mnie, ale był ludzki, nie formalny. Bo kolonia jest im mimo wszystko potrzebna. Sprawa jest bardzo skomplikowana. Poza tym widzą, że my dla nich pracujemy. Przecież są jednak ludźmi. To ważna okoliczność (Makarenko 1949: I, 24).

Powyższy dialog ma też miejsce w filmie - w bardzo podobnej formie. Tu jednak w usta Makarenki scenarzyści wkładają następującą kluczową puentę. Wypowiada ją wprawdzie w zamyśleniu, ale w zdecydowany, pozbawiony emocji sposób. Oko kamery w zbliżeniu śledzi wówczas jego rozświetloną promieniem lampy naftowej twarz, kontrastującą z ciemnością pokoju, w którym odbywa się rozmowa. Jego kwestia brzmi:

- Ograniczać się tylko do litości dla naszych wychowanków nie mamy prawa. Dla ich wyzwolenia [ros. spasienija] musimy być niewzruszenie wymagający, surowi i twardzi. Dopóki nie znajdziemy innej metody (Piedagogiczeskaja poema, 1955).

W ten oto sposób realizowany jest wspomniany już mitologem człowieka radzieckiego. Rosyjskie spasienije przetłumaczyłem w neutralny sposób jako „wyzwolenie” - tak zapewne postąpiłby po analizie kontekstu tłumacz filmu w latach pięćdziesiątych. Rzeczownik ten ma jednak dwa znaczenia - w zasobie języka ogólnego oznacza ratunek, występuje jednak również w języku religijnym, oznaczając zbawienie. Pojawienie się takiego właśnie słowa w filmie totalitarnym nieuchronnie przyczynia się do właśnie soteriologicznego zabarwienia frazy. Mowa oczywiście nie o zbawieniu chrześcijańskim, lecz radzieckim - o uwolnieniu całego potencjału jednostki po tym, gdy duchowo zespoli się ona ze wspólnotą posiadaczy „świadomości bolszewickiej”. Ten sam filmowy Zadorow, przemawiający do nowych kolonistów w Kuriażu, będzie już postacią odmienioną, „przebóstwioną” przez pełne odnalezienie się w radzieckiej wspólnocie. Dodajmy jeszcze, że sentencja „dla ich wyzwolenia musimy być niewzruszenie wymagający, surowi i twardzi" - to element totalitarnokulturowego komunikatu, w którym realizuje się ten sam mitologem. „Surowość i twardość” władzy jest tym depozytem, który należy bezwarunkowo przyjąć, by być pełnym beneficjentem radzieckiego porządku świata, czyli - „człowiekiem radzieckim”, wyzwolonym czy zbawionym. Dodajmy, że dla deklaracji filmowego Makarenki o „surowości i twardości... dopóki nie znajdziemy innej metody” twórcy scenariusza znaleźli „,alibi” w konstatacji narratora literackiego Poematu: „Postanowiłem, że jeśli nie uda mi się zastosować innej metody, będę dyktatorem" (Makarenko 1949: I, 23). To wyznanie ma jednak wymiar swoistej kapitulacji Makarenki przed sobą samym, podczas gdy z deklaracji filmowej przebija pewność i - znowuż - „świadomość bolszewicka". To kolejny efekt transformacji tekstu niemającego cech totalitarnych na potrzeby dyskursu kultury stalinowskiej. 
Sformułowana w niniejszym tekście teza nietotalitarnego charakteru tekstu wyjściowego Poematu pedagogicznego znajduje potwierdzenie w fakcie, iż wprowadzenie go do filmowego dyskursu totalitarnego - nawet w ostatnich miesiącach funkcjonowania stalinowskiego paradygmatu kulturowego - wymagało jednak inkorporowania do fabuły jednego epizodu o wyraźnym zabarwieniu ideologicznym, politycznym i oczywiście mitologicznym. Mowa o scenie, w której w Kolonii im. Gorkiego odbywa się spotkanie, które można określić mianem zajęć z politgramoty. Makarenko, trzymając w ręku numer „Prawdy”, opowiada wychowankom o szacunku Lenina dla młodzieży, która wsparła bolszewików w wojnie domowej i o apelu wodza rewolucji, by po wywalczonym zwycięstwie stanęła w szeregach nowej armii - armii pracy. W ten sposób cała fabuła Makarenkowskiego wychowania przez pracę uzyskuje mitologiczną perspektywę narracyjną, ujawnioną chociażby w słowach marszu, towarzyszącego „gorkowcom” w uroczystym wejściu do Kuriażu:

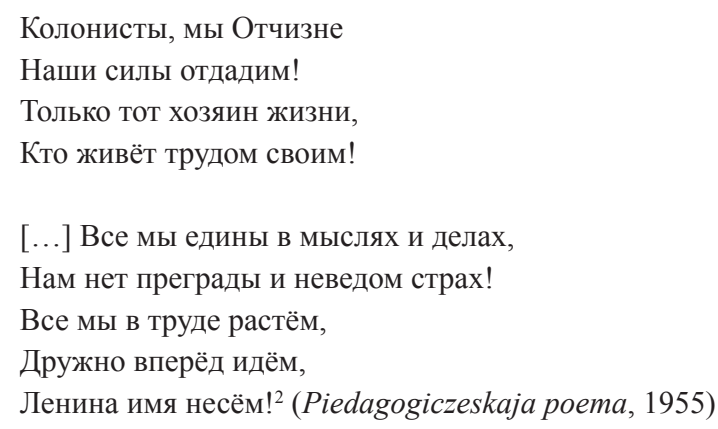

W powyższych słowach życie i praca wychowanków Makarenki uzyskują wyraźny opis światopoglądowy, w którym mitologem pracy i mitologiczna figura Lenina stają się elementami umiejscowienia zarówno resocjalizacji jako takiej, jak i wspólnych wysiłków zresocjalizowanej młodzieży w systemie totalitarnokulturowej kosmologii. Nie inaczej będzie w przypadku „święta pierwszego snopa”. W połowie trzeciej części Poematu Makarenko umieścił opis wypracowanego w kolonii rytuału początku żniw. Rytuał ten przez scenarzystów filmu został wykorzystany w finale jako puenta całości narracji - zgodnie z konwencją kina socrealistycznego, nakazującą, by obrazy filmowe kończyć sceną wykraczającą poza fabułę, stawiającą narracyjną kropkę nad ,i”, porządkującą świat, a ściślej - synchronizującą świat ukazany w fabule z mitologicznymi wyobrażeniami kultury totalitarnej. W przypadku filmowego Poematu pedagogicznego finał stanowi rozbudowaną oprawę mitologemu pracy socjalistycznej.

Dokonana tutaj analiza wybranych aspektów relacji wzajemnych literackiego pierwowzoru i samego filmu dowodzi, że transformacja tekstu literackiego na kinematograficzny

2 Tłum. filologiczne: Koloniści, my Ojczyźnie / oddamy nasze siły! / Tylko ten jest panem swego życia, / Kto żyje własną pracą! // [...] Wszyscy jesteśmy zjednoczeni myślą i pracą, / Nie znamy przeszkód ani strachu! / Wszyscy dojrzewamy w pracy, / Razem kroczymy naprzód, / Niesiemy imię Lenina! 
ma w tym przypadku charakter złożony. Nie wynika jedynie z konieczności dostosowania tekstu wyjściowego do językowych wymogów dzieła filmowego. Typologiczna różnica języka Makarenki oraz Maslukowa i Majewskiej dotyczy nie tylko dwóch sfer funkcjonowania stworzonych przez nich tekstów, ale i dwóch typów kultury, w których powoływane były do życia. Wydany drukiem w latach 1934-1935 Poemat pedagogiczny powstały jako dzieło autonomiczne wobec dyskursu totalitarnego, mimo wszystko w nim uczestniczy w formie odpowiednio „odfiltrowanej” i zresemantyzowanej. Klucz jego odczytu przez użytkowników języka totalitarnego jest specyficzny. Jaki to klucz - w znacznym stopniu wyjaśnia nasza analiza transformacji filmowej.

\section{Literatura}

Makarenko A. (1949), Poemat pedagogiczny. T. I-III. Warszawa, Książka i Wiedza.

Makarienko A.S. (2003), Piedagogiczeskaja poema. S. Niewskaja (red.). Moskwa, ITRK.

Michajlin W., Bielajewa G. (2014), „Po prijutam ja s dietstwa skitatsja”. Pieriekowka biesprizornikow w sowietskom kino. http://www.strana-oz.ru/2014/2/po-priyutam-ya-s-detstva-skitalsya (dostęp: 14.08.2017).

Niewskaja S.S. (2003), Ot sostawitiela. „Piedagogiczeskaja poema” i proza żizni Antona Makarienko (,,Poema” o bolszoj lubwi k czełowieku). W: A.S. Makarienko (2003), Piedagogiczeskaja poema. S. Niewskaja (red.). Moskwa, ITRK.

Piedagogiczeskaja poema (1955). A. Maslukow, M. Majewskaja (reż.), I. Maniewicz, A. Maslukow (scen.). ZSRR, Kijewskaja kinostudija chudożestwiennych fil'mow.

Pierwyj wsiesojuznyj sjezd sowietskich pisatielej. Stienograficzeskij otczot (1935). Moskwa, Gosudarstwiennoje izdatielstwo „Chudożestwiennaja litieratura”.

Sadowski J. (2005), Rewolucja i kontrrewolucja obyczajów. Rodzina, prokreacja i przestrzeń życia w rosyjskim dyskursie utopijnym lat 20. i 30. XX w. Łódź, Wydawnictwo Naukowe Ibidem.

Sadowski J. (2009), Między Pałacem Rad i Pałacem Kultury. Studium kultury totalitarnej. Kraków, Egis.

Sadowski J. (2017), „Krótki kurs” historii WKP(b) i problem narracji totalitarnej. „Slavia Orientalis", LXVI, 2. 